\title{
Cooperación Internacional para la Prevención de los Delitos Transnacionales
}

\author{
Por: Alberto Luis Escobar Ceballos \\ Abogado Universidad Santo Tomás - Especialista en Derecho Penal - \\ Candidato a Magíster en Derecho Penal - Director Centro de Investigaciones \\ Socio- jurídicas Jorge Eliécer Gaitán - UNIMETA
}

\section{INTRODUCCIÓN}

Una vez entró en vigencia la Convención de las Naciones Unidas contra la Delincuencia Organizada Transnacional - D.O.T, se esperaba poder prevenir y combatir más eficazmente la delincuencia. La D.O.T. dotó a los Estados miembros de las Naciones Unidas de un amplio marco jurídico para combatir a la delincuencia organizada, que incluye instrumentos como la extradición y asistencia jurídica en materia penal, así como nuevos métodos y técnicas de investigación, aseguramiento de los bienes que se utilizan para cometer el delito o aquellos que son producto de éste.

\section{ABSTRACT}

Once entered into force the United Nations Convention against Transnational Organized Crime, is hoping to prevent and combat crime more effectively. The D.O.T. provided to Member States of the United Nations of a comprehensive legal framework to fight organized crime, which includes instruments such as extradition and legal assistance in criminal matters, as well as new methods and techniques of research, assurance that assets are used to commit the crime or those who are of this product.

\section{PALABRAS CLAVES}

Cooperación, Delincuencia, Delincuencia Transnacional Organizada, Delito, Estado, Internacional, Grupo Delictivo, Naciones Unidas.

\section{KEYWORDS:}

Cooperation, Crime, TransnationalOrganizedCrime, Crime, State, International criminal groups, United Nations.
La Delincuencia Organizada Transnacional - D-O.T es una de las amenazas más graves para la seguridad pública y nacional. Las antiguas organizaciones delincuenciales tenían un alcance muy limitado, su campo de acción era local, pero en este mundo globalizado las cosas han cambiado y ahora lo que antes era un asunto local se ha convertido en tema que atañen a muchos países pasando de ser de la incumbencia nacional a una importancia transnacional.

\section{NOTA}

Transnacional y multinacional son sinónimos que literalmente significan "de varias naciones o relativo a ellas", pero en el ámbito del derecho penal cuando se usa la expresión transnacional se hace referencia a delitos o acciones que se desarrollan o tienen incumbencia en el territorio de dos o más países.

"El problema del crimen en el mundo interesa a la ONU por muchas razones. Evidentemente, está directamente vinculado al objetivo principal de la Organización de sus Estados miembros: la paz mundial. Porque la paz es indivisible y no puede considerarse independientemente de la acción recíproca de los pueblos, tanto en la esfera interna, como a un lado y otro de las fronteras. Cabe pensar que media una gran distancia entre los crímenes cometidos por asociaciones de delincuentes, los robos a mano armada, los abusos de confianza y la diplomacia internacional y las negociaciones entre los miembros del Consejo de Seguridad. Sin embargo, los asesinatos, la piratería, los secuestros internacionales han causado guerras. Hoy en día el tráfico ilícito de estupefacientes, el contrabando de armas, las exportaciones ilegales de oro, el secuestro de diplomáticos, el desvío de aeronaves y su sabotaje, la protección concedida a los criminales que huyen, constituyen causas de tensión y conflictos internacionales..." 1 
ISSN-2248-736 * Número 3 * Revista Facta Non Verba

La delincuencia tiende a ampliarse, cobrando más fuerza y volviéndose más compleja. Debido a esto, cada vez más es una amenaza contra los pueblos y un obstáculo para el desarrollo socioeconómico de los países. La delincuencia ha evolucionado hasta volverse transnacional y ampliar su ámbito de operaciones que comprenden el tráfico de armas, el blanqueo de dinero y el tráfico de migrantes.

Como claramente lo explica el doctor Moya en su artículo "Fundamentos teórico prácticos para un análisis crítico de las relaciones judiciales internacionales en materia penal con autoridades extranjeras", en un mundo globalizado como en el que vivimos, el delito ha dejado de ser asunto de un solo Estado, ya que en la comisión del mismo, lo normal es que solo suceda en el territorio de un país, pero con la tendencia actual de la globalización ha dejado de ser una constante para convertirse en una excepción. Se podría decir que hoy es común que un delito suceda en varios territorios de Estados diferentes, por tal razón se hace necesaria la colaboración de todos los miembros de la Convención de la D.O.T.

Los Estados al hacer parte de la Convención D.O.T. no pierden su soberanía, pero dejar que otro Estado literalmente se entrometa en asuntos que serían propios, es un problema netamente de jurisdicción, por lo cual según palabras del doctor Moya Vargas "En cuanto a los delitos que suceden total o parcialmente en territorio extranjero, el déficit del derecho internacional es notorio. Si bien algunos instrumentos como la Convención de Viena sobre relaciones diplomáticas y la de relaciones consulares, definieron claramente los criterios de jurisdicción, los mismos se contraen a eventos asociados a las hipótesis en que los agentes diplomáticos y consulares incurrieren en reatos dentro el territorio del estado en que están ejecutando la representación."

Ahora bien, surge la necesidad de crear una reglamentación sobre la Delincuencia Organizada Transnacional en la cual cada Estado pueda combatir al crimen en su territorio y a la vez pueda colaborar con otros Estados para tratar de prevenir que se cometan delitos que atañen o sucedan en dos o más países; como lo menciona el doctor Jean Pierre Matus en su artículo sobre " $\mathrm{La} P \mathrm{Po}$ lítica Criminal de los Tratados Internacionales" "Werle denomina al conjunto de normas que se derivan de este variopinto grupo de convenciones y tratados, derecho de los "crímenes de trascendencia internacional" (International Crimes), entre los cuales cabría distinguir claramente aquéllos que podemos denominar "Crímenes de derecho internacional" (Crimes under international law), que son penalizados directamente por el Derecho internacional y por organismos internacionales (como sucede típicamente con los delitos de lesa humanidad y demás crímenes internacionales reconocidos en el Estatuto de Roma); del resto de los crímenes de trascendencia internacional, respecto de los cuales el Derecho internacional impondría únicamente obligaciones de implementación de la penalización de determinadas conductas conforme al derecho interno de cada Estado, como sucede típicamente con las Convenciones de Viena de 1998 y de Palermo de 2000, contra el Tráfico Ilícito de Estupefacientes y contra la Delincuencia Organizada Transnacional, respectivamente". 3

Si bien es cierto lo que plantea en su artículo el doctor Matus sobre las obligaciones impuestas a los Estados para penalizar ciertas conductas, no menos cierto es que la principal función de la convención de la D.O.T. es tratar de conformar un bloque de delitos que tengan el mismo tratamiento independientemente del Estado en el cual se cometa el mismo. Según el mismo autor "Una característica del conjunto de las convenciones y tratados que regulan los "crímenes de trascendencia internacional" que no constituyen "crímenes de derecho penal internacional" ni son parte de un "derecho penal supranacional", es que en general sus normas no son "autoejecutables" (self'executing) sino obligaciones internacionales de diferente intensidad (según la clasificación de Virally: "invitaciones a observar comportamientos", "obligaciones de desarrollo discrecional", "obligaciones generales no concretadas", y "obligaciones concretas"), que en todo caso se encuentran necesitadas de implementación por parte de los Estados suscriptores, conforme a su propio sistema jurídico. Sin embargo, en la actualidad, dichos tratados y convenciones regularmente emplean mecanismos que van más allá de entregar su implementación a la interpretación que cada Estado haga de sus normas y a la vigilancia informal del conjunto de la comunidad internacional, recurriendo para ello a "técnicas organizadas": de una parte, mediante "técnicas convencionales", obligando a

2. FUNDAMENTOS TEÓRICO PRÁCTICOS PARA UN ANÁLISIS CRÍTICO DE LAS RELACIONES JUDICIALES INTERNACIONALES EN MATERIA PENAL CON AUTORIDADES EXTRANJERAS; MOYA, Manuel Fernando, Bogotá 2009.

3.La Política Criminal de los Tratados Internacionales; MATUS Jean Pierre, Revista Ius et Praxis, Talca - Chile, 2007 
que los Estados Parte informen periódicamente de los avances en la materia a alguna autoridad designada (Secretaría General, Conferencia o Asamblea de las Partes, etc.) en el Tratado respectivo para controlar su implementación." 4

No cabe duda sobre la importancia de la convención de las Naciones Unidas sobre la Delincuencia Organizada Transnacional, y mucho menos sobre que deben hacer los países miembros para combatir el flagelo de la delincuencia transnacional, ya que la misma convención les da las pautas a cada Estado participe, pautas que no son del todo obligatorias, pero que si se deben tener en cuenta si queremos ganarle la batalla a la delincuencia organizada transnacional.

Esto nos demuestra que cada Estado parte de la Convención D.O.T. es libre de implementar los mecanismos necesarios para combatir los llamados por el doctor Matus, Delitos de Trascendencia Internacional.

\section{DELITOS DE TRASCENDENCIA INTERNACIONAL}

Otro aspecto importante de la D.O.T. es lo referente a los delitos, pero no todo tipo de delitos, sino aquellos que el docto Matus cataloga como de trascendencia internacional. Estos constan de un aspecto objetivo y uno subjetivo.

"En su aspecto objetivo, los delitos de trascendencia internacional exigen la externalización de una conducta humana, aunque ésta puede tomar varias formas, según la materia de regulación: puede tratarse de un acto del habla (Por ejemplo en el soborno de funcionarios públicos: "la promesa" "y "el ofrecimiento" de un beneficio indebido), de una vinculación subjetiva con un objeto ilicito (la "posesión" de estupefacientes para su "consumo personal"), de una acción material, con o sin resultado separable de la misma (falsificación de documento, destrucción de medios de transporte). Además, en general, las descripciones típicas que se proponen a los Estados parte, basadas en el interés de no dejar "lagunas de punibilidad", son extremadamente detallistas y fatigosas, por lo que a su respecto no parece del todo aplicable el temor de que en su implementación se lesione el principio de determinación o tipicidad, sino al contrario: lo más probable es que al implementarse en sistemas legalistas, el excesivo detalle lleve a dejar lagunas de punibilidad. ${ }^{5}$

Los delitos de trascendencia internacional exigen que la figura de la "intencionalidad" este presente en prácticamente todas las figuras penales.

Pero surge entonces una pregunta ¿Qué es la intencionalidad? La intencionalidad (del latín in-tendere, "tender hacia") es un término filosófico que se refiere tanto al contenido de la mente o la conciencia, como a la relación entre la conciencia y el mundo. Fundamentalmente, la intencionalidad significa que la actividad de la mente se refiere a, indica o contiene un objeto. Desde otro punto de vista, se puede decir que un sujeto es capaz de conocer la realidad que lo circunda y que además tiende naturalmente hacia ella. (www.wikipedia.org).

Ahora, para que no quede duda de que la intencionalidad es diferente de otros ánimos exigidos o del conocimiento de ciertos elementos del tipo, muchas figuras penales agregan el requisito de actuar, ósea que la persona debe poner en marcha una serie elementos que podrían ser del orden mecánico "con el propósito de" o del tipo cognoscitivo "a sabiendas de", conocer del hecho delictivo que se va a realizar.

Haciendo una referencia específica, los delitos que se encuentran tipificados en la convención, necesitan que exista el acuerdo y/o participación de varias personas,

4.La Política Criminal de los Tratados Internacionales; MATUS Jean Pierre, Revista Ius et Praxis, Talca - Chile, 2007

NOTA: Artículos 8 y 13 Convención contra la Delincuencia Transnacional Organizada

8. Al establecer sus prioridades, los legisladores nacionales deberán tener presente que las disposiciones de la Convención y de sus Protocolos no tienen todas el mismo grado de obligación. En general, las disposiciones pueden agruparse en las tres categorías siguientes:

a) Medidas que son obligatorias (ya sea absolutamente o cuando se hayan cumplido determinadas condiciones);

b) Medidas cuya aplicación los Estados Parte deben considerar o procurar;

c) Medidas que son facultativas"

Y en cuanto al modo de hacer cumplir las obligaciones de tipificación en particular, se agrega:

"13. Se recomienda que los legisladores verifiquen la coherencia con otros delitos, definiciones y usos legislativos antes de emplear las formulaciones o la terminología de la Convención. La Convención se redactó con fines generales y va dirigida a los gobiernos nacionales. Por consiguiente, su nivel de abstracción es mayor que el necesario para la legislación interna. De ahí que los legisladores deban tener cuidado de no incorporar literalmente partes del texto. En lugar de ello, se les anima a que capten el espíritu y significado de los distintos artículos...” 


\section{ISSN-2248-736 * Número 3 * Revista Facta Non Verba}

, para que se pueda configurar un grupo delictivo organizado, además se necesita que el propósito por el cual esas personas se asocian sea el de cometer un delito y que este último represente un beneficio económico o de cualquier otra índole.

La participación del miembro dentro del grupo delictivo debe ser activa, ya sea en las actividades ilícitas realizadas por el grupo, o cualquier otro tipo de participación con la cual se garantice la comisión del delito, como la organización, la facilitación, el asesoramiento entre otras conductas que vienen tipificadas en la convención. Se entiende por participación en un grupo delictivo organizado: La organización, dirección, ayuda, incitación, facilitación o asesoramiento en aras de la comisión de un delito grave que entrañe la participación de un grupo delictivo organizado.

Así mismo los Estados parte que decidieron adoptar la Convención D.O.T. se han dado cuenta que la forma más efectiva de contrarrestar la delincuencia transnacional organizada es la de atacar su capacidad económica; es por eso que los Estados parte adoptaron medidas contra el lavado o blanqueo de dinero, medidas contra la corrupción; métodos estos eficaces en la lucha por acabar con el flagelo de la delincuencia.

Que los Estados Parte en la Convención de la Naciones Unidas contra la Delincuencia Transnacional Organizada cooperen entre sí para luchar contra este mal, no indica que estos pierdan su soberanía, por el contrario, la misma convención propende por que cada Estado Parte sea capaz de interactuar con otro sin que se sufra una intromisión en la soberanía de otro.

\section{HIPÓTESIS DE COMPETENCIA}

Una hipótesis puede definirse como proposición cuya veracidad es provisionalmente asumida, como solución provisional (tentativa) para un problema dado o con algún otro propósito investigativo. El nivel de verdad que se asume para una hipótesis dependerá de la medida en que los datos empíricos recogidos apoyen lo afirmado en la hipótesis. (www.wikipedia.org)

Para poder llevar a cabo todos los lineamientos propuestos por la D.O.T. es necesario que hablemos de la Cooperación Internacional y de las hipótesis que se manejan en este tema.

Dentro de la Cooperación Internacional hay que destacar la existencia de un Estado requirente, aquel que realiza o eleva una petición a otro Estado el cual se denomina Estado Requerido.

En lo que hace referencia a Cooperación en la Convención de las Naciones Unidas contra la Delincuencia Organizada Transnacional podemos decir lo siguiente:

\section{Se aplica el intercambio de información}

\section{Se aplica la extradición}

\section{Se aplica la remisión de procesos}

\section{Se llevan a cabo acciones conjuntas}

5. Se aplica la cooperación para el decomiso.

NOTA: Artículos 5, 6, 8 y 23 Convención contra la Delincuencia Organizada Transnacional

ART. 5 A. I. El acuerdo con una o más personas de cometer un delito grave con un propósito que guarde relación directa o indirecta con la obtención de un beneficio económico u otro beneficio de orden material y, cuando así lo prescriba el derecho interno, que entrañe un acto perpetrado por uno de los participantes para llevar adelante ese acuerdo o que entrañe la participación de un grupo delictivo organizado.

A.II. La conducta de toda persona que, a sabiendas de la finalidad y actividad delictiva general de un grupo delictivo organizado o de su intención de cometer los delitos en cuestión, participe activamente en:

a. Actividades ilícitas del grupo delictivo organizado;

b. Otras actividades del grupo delictivo organizado, a sabiendas de que su participación contribuirá al logro de la finalidad delictiva antes descrita.

B. La organización, dirección, ayuda, incitación, facilitación o asesoramiento en aras de la comisión de un delito grave que entrañe la participación de un grupo delictivo organizado.

ART. 6.A.I. La conversión o la transferencia de bienes, a sabiendas de que esos bienes son producto del delito, con el propósito de ocultar o disimular el origen ilícito de los bienes o ayudar a cualquier persona involucrada en la comisión del delito determinante a eludir las consecuencias jurídicas de sus actos.

II. La ocultación o disimulación de la verdadera naturaleza, origen, ubicación, disposición, movimiento o propiedad de bienes o del legítimo derecho a éstos, a sabiendas de que dichos bienes son producto del delito

B.I. La adquisición, posesión o utilización de bienes, a sabiendas, en el momento de su recepción, de que son producto del delito

ART.8.A.I. La promesa, el ofrecimiento o la concesión a un funcionario público, directa o indirectamente, de un beneficio indebido que redunde en su propio provecho o en el de otra persona o entidad, con el fin de que dicho funcionario actúe o se abstenga de actuar en el cumplimiento de sus funciones oficiales 
En tanto es posible manejar tres tipos diferentes de hipótesis: Las de Competencia Obligatoria, las de Competencia Condicionada y las de Competencia Sucedánea.

Las hipótesis mencionadas sirven para identificar cual sería la jurisdicción aplicable a un caso concreto, ya que los delitos se cometen en territorios de varios Estados a la vez directa o indirectamente, es necesario saber cual seria la ley aplicable al caso en particular.

En las primeras el delito del que se trata debe ser cometido en el territorio de un Estado determinado o se aplique el principio de extraterritorialidad cuando el delito se ha cometido a bordo de un buque o aeronave; o que el delito se cometa contra un nacional en territorio extranjero. En la Convención D.O.T. encontramos lo siguiente:

Hipótesis de Competencia Obligatoria:

\section{El delito se cometa en su territorio.}

2. El delito se cometa a bordo de un buque que enarbole su pabellón o de una aeronave registrada conforme a sus leyes en el momento de la comisión del delito.

3. El delito se cometa contra uno de sus nacionales.

En las segundas, ósea las Hipótesis de Competencia Condicionada, los Estados condicionan la colaboración y cooperación a otros Estados.

Estas condiciones pueden variar según las relaciones internacionales de cada Estado. Dentro de la Convención D.O.T. encontramos el siguiente ejemplo de Hipótesis de Competencia Condicionada:

\section{Hipótesis de Competencia Condicionada:}

1. Los Estados Parte podrán denegar la cooperación solicitada con arreglo al presente artículo si el delito al que se refiere la solicitud no es un delito comprendido en la presente Convención.

2. El delito sea cometido por uno de sus nacionales o por una persona apátrida que tenga residencia habitual en su territorio.
En las Terceras Hipótesis los Estados que reciban una solicitud por parte de otro Estado, estas pueden ser modificadas y/o aceptadas tal cual se hace la solicitud.

El Estado requerido deberá hacer un análisis consensual de lo que se le esta requiriendo y posteriormente aceptará o modificará ese requerimiento. En la convención D.O.T. encontramos lo siguiente:

Hipótesis de Competencia Sucedánea:

1. Los Estados Parte que reciban una solicitud de otro Estado Parte que tenga jurisdicción para conocer de un delito comprendido en la presente Convención con miras al decomiso del producto del delito, los bienes, el equipo u otros instrumentos mencionados en el párrafo 1 del artículo 12 de la presente Convención que se encuentren en su territorio deberán, en la mayor medida en que lo permita su ordenamiento jurídico interno.

2. A raíz de una solicitud presentada por otro Estado Parte que tenga jurisdicción para conocer de un delito comprendido en la presente Convención, el Estado Parte requerido adoptará medidas encaminadas a la identificación, la localización y el embargo preventivo o la incautación del producto del delito, los bienes, el equipo u otros instrumentos mencionados en el párrafo 1 del artículo 12 de la presente Convención con miras a su eventual decomiso, que habrá de ordenar el Estado Parte requirente o, en caso de que medie una solicitud presentada con arreglo al párrafo 1 del presente artículo, el Estado Parte requerido.

3. La Extradición: Es el procedimiento por el cual una persona acusada o condenada por un delito conforme a la ley de un Estado es detenida en otro y devuelta para ser enjuiciada o que cumpla la pena ya impuesta. (www. wikipedia.org)

Muyapesar que se está dandouna cooperacióninternacional muy activa para la represión y prevención de los delitos a nivel mundial, continúa existiendo la regla de que un

B. La solicitud o aceptación por un funcionario público, directa o indirectamente, de un beneficio indebido que redunde en su propio provecho o en el de otra persona o entidad, con el fin de que dicho funcionario actúe o se abstenga de actuar en el cumplimiento de sus funciones oficiales

ART.23.A. El uso de fuerza física, amenazas o intimidación, o la promesa, el ofrecimiento o la concesión de un beneficio indebido para inducir a falso testimonio u obstaculizar la prestación de testimonio o la aportación de pruebas en un proceso en relación con la comisión de uno de los delitos comprendidos en la presente Convención.

B. El uso de fuerza física, amenazas o intimidación para obstaculizar el cumplimiento de las funciones oficiales de un funcionario de la justicia o de los servicios encargados de hacer cumplir la ley en relación con la comisión de los delitos comprendidos en la presente Convención. Nada de lo previsto en el presente apartado menosca- 


\section{ISSN-2248-736 * Número 3 * Revista Facta Non Verba}

la regla de que un Estado está obligado a conceder la extradición de un delincuente extranjero, solamente si existe tratado internacional vigente con el Estado que requiere la extradición. Cuando no hay tratado, el Estado requerido está facultado para acordar la extradición, pero no está obligado a concederla, lo que genera en algunos casos ciertos impedimentos del orden de cooperación internacional de carácter recíproco.

2. Los Estados Parte podrán considerar la posibilidad de celebrar acuerdos o arreglos bilaterales o multilaterales sobre el traslado a su territorio de toda persona que haya sido condenada a pena de prisión o a otra pena de privación de libertad por algún delito comprendido en la presente Convención a fin de que complete allí su condena.

Hemos visto a través de este escrito la verdadera importancia de la convención, la cooperación internacional es la única manera de poder acabar con la delincuencia transnacional, sin el temor de perder la soberanía de cada Estado partícipe.

Hemos destacado aspectos importantes, algunos innatos al ser humano, en cuanto a su voluntad de ser parte o partícipe de una organización de carácter delincuencial, la forma en que puede participar y como ha de desarrollar esa participación.

Pero no solo vimos a la persona, también vimos a los Estados víctimas de este flagelo, las formas en las cuales pueden colaborarse entre sí. Además dimos un breve vistazo por las opciones que tienen los países en cuanto a cooperación internacional y a las hipótesis de competencia, y sobretodo recalcamos la importancia de que todos los países deben estar de acuerdo en la forma como se intenta prevenir el delito y como atacarlo cuando este se presenta ya no como un hecho aislado correspondiente a un solo Estado, sino que se manifiesta como un cúmulo de actividades que se desarrollan en diferentes territorios de países que en ocasiones ni siquiera tienen límites territoriales.

De ahí la importancia que cada día más adquiere la convención de la D.O.T., ya que como se mencionó al principio de este artículo, el delito ha dejado de ser eminentemente local, para convertirse en transnacional.
FUENTES

1. CUARTO CONGRESO DE LAS NACIONES UNIDAS SOBRE PREVENCIÓN DEL DELITO Y TRATAMIENTO DEL DELINCUENTE. CLIFFORD, William. Secretario Ejecutivo del realizado en Kyoto (Japón) entre el 17 y el 26 de agosto de 1970.

2. FUNDAMENTOS TEÓRICO PRÁCTICOS PARA UN ANÁLISIS CRÍTICO DE LAS RELACIONES JUDICIALES INTERNACIONALES EN MATERIA PENAL CON AUTORIDADES EXTRANJERAS. MOYA, Manuel Fernando. Bogotá 2009.

3. LA POLÍTICA CRIMINAL DE LOS TRATADOS INTERNACIONALES. MATUS. Jean Pierre. Revista Ius et Praxis. Talca - Chile, 2007

4. CÓDIGO PENAL COLOMBIANO. LEY 599 DE 2000.

5. CONVENCIÓN DE LAS NACIONES UNIDAS CONTRA LA DELINCUENCIA ORGANIZADA TRANSNACIONAL. 15 de noviembre de 2000.

6. LA POLÍTICA CRIMINAL DE LOS TRATADOS INTERNACIONALES. MATUS, J. P.

7. LA CONVENCIÓN DE LAS NACIONES UNIDAS CONTRA LA DELINCUENCIA TRANSNACIONAL ORGANIZADA Y SUS PROTOCOLOS ADICIONALES. UN NUEVO MARCO DE COOPERACIÓN INTERNACIONAL. Nicolin, E. I.

8. TRABAJOS PREPARATORIOS CONVENCIÓN DE LAS NACIONES UNIDAS CONTRA LA DELINCUENCIA TRANSNACIONAL ORGANIZADA. 17 a 28 de julio de 2000. Viena.

9. CONFINES INTERNACIONALES DE LA JURISDICCIÓN PENAL. REVISTA ELECTRÓNICA DE LA ASOCIACIÓN ESPAÑOLA DE PROFESORES DE DERECHO INTERNACIONAL. Vargas, M. F. 2003.

WEBGRAFÍA

1. www.un.org/Spanish

2. www.wikipedia.org

3. www.bibliojuridica.org

4. www.unodc.org

5. www.uncjin.org

6. www.gloobal.net

7. www.cinu.org. $\mathrm{mx}$

8. www.acnur.org 